\title{
Research on the Degree of Confidence of the Commodity Based on Fuzzy Comprehensive Evaluation
}

\author{
Mingshan $x^{1} e^{1, a}$, Yanfang Deng ${ }^{2, b}$ * \\ ${ }^{1}$ College of network, Haikou College of Economics, China \\ ${ }^{2}$ Hainan University, China \\ a283921977@qq.com, ${ }^{\text {b 271190993@qq.com }}$
}

\begin{abstract}
Keywords: Fuzzy comprehensive evaluation; commodity confidence prototype; commodity attribute Abstract. In order to enhance the accuracy of precision marketing of goods and improve the precision of the intelligent search engine, we build the confidence model of commodity by means of using the fuzzy comprehensive evaluation method, to calculate the commercial confidence, which can be used as the foundation of the commodity precision marketing and recommendation computation.
\end{abstract}

\section{Introduction}

There is a lot of research on user interest model in the field of product precision marketing system and commodity intelligent search engine. However, the relationship of the product and the user is mutual, in intelligent information processing technology, the user and the product are bidirectional. Once users need to buy goods, they search for a large number of goods, concerned about their own interest in the goods, and then buy and use their own needs. In this scenario, the modern intelligent information technology can make the goods to match the certain needs of user group and make judgments, so that the product to seek its users. Their relationship is shown in Figure 1.

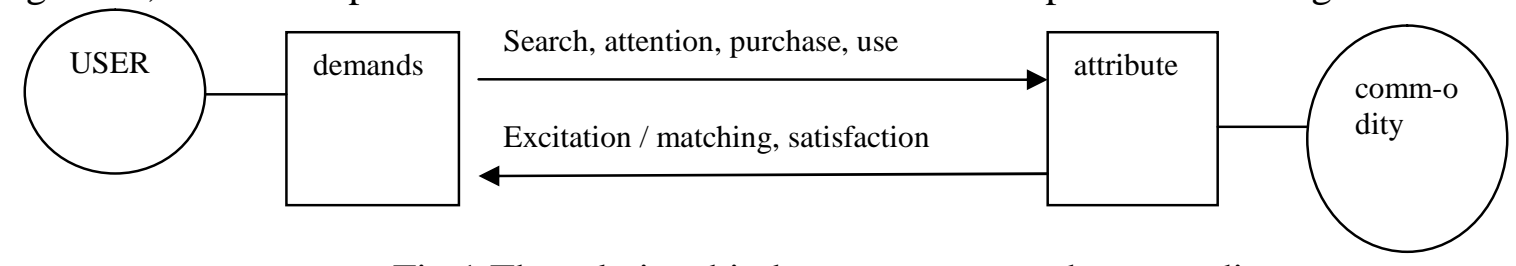

Fig.1 The relationship between users and commodity

Now a lot of researches only focus on users, but not many studies have focused on commodities. Only a few scholars study the commodity is also from the perspective of commodity ontology to study. For example, Liu Dan, et al. Established the ontology model of the expression of a single product, considered the product inheritance relationship in [2]; Australia scholar HEPP, based on eCl@ SS, released a product ontology OWL language in[3]. South Korean scholars LEE and so on proposed to increase the product attribute in the UNSPSC standard, designed a relatively complete product ontology model in the papers[4-6]. VEGETTI et al. Study the method of extracting the commodity structure from the PDM system in[7]. RAYMOND proposed the idea of the concept and classification of goods from the ontology in the paper[8]. Their studies are lack of consideration for the commodity, the commodity has its own physical properties, but also has its social attributes. They are still looking at the relationship between the product and the user. To solve these problems, the author used fuzzy comprehensive evaluating of commercial building confidence model in intelligent information processing technology, so that the product with its own attribute goods took the initiative to find user in commodity precise recommendation system and commercial intelligent search engine, improved recommendation accuracy and search precision.

\section{Fuzzy comprehensive evaluation method}

Fuzzy comprehensive evaluation method is a method of fuzzy theory. Fuzzy theory and rough set theory, neural network and other disciplines are intelligent information processing technology research field, in which fuzzy in fuzzy comprehensive evaluation method should be very wide. 


\section{Analysis of commodity confidence model}

Intelligent information processing technology needs to give the product a certain wisdom and self-awareness. Our research on the information processing of the commodity need to be resolved from the perspective of human nature, the concept of the introduction of the commodity confidence model.

The definition of the product's confidence model is that the evaluation of the product itself to the user's degree of application and user acceptance, according to their own inherent properties and the external visibility. In the commodity confidence model, the author uses the commodity confidence to measure the degree of application and user acceptance of the product. The confidence model of commodity is the first consideration of commodity recommendation and commodity search, but also the basis of product recommendation. The recommendation degree of the product is based on the confidence of the model. Commercial confidence degree by using the probability theory of thought, with uncertainty, drawn under different application scenarios and examine granularity on the same commodity confidence degree can be not the same, for commercial properties and processing merchandise information application system. The confidence model of the commodity varies with the intensity of the advertising and the property of the commodity.

\section{Calculation of commodity confidence}

\section{Influence degree of advertisement propaganda mode}

User's choice of goods is very much influenced by the way of the commodity advertisement. Most people tend to choose the commodities with high visibility. The Degree of selection of products with high visibility is higher than the degree of selection of the products with low visibility. The author uses $w$ to express a variety of advertising methods. Therefore, the vector of advertising style influence degree is denoted by $\mathrm{W}=\left(\mathrm{w}_{1}, \mathrm{w}_{2}, \mathrm{w}_{3}, \ldots \ldots \mathrm{w}_{\mathrm{n}}\right)$. Among them, $\mathrm{n}$ means the total number of ads. $\mathrm{w}_{\mathrm{k}}$ means the kth method of advertising, and the return value is a Boolean, so takes 0 or 1 . The equation $\mathrm{w}_{\mathrm{k}}=0$ means that sellers chose the $\mathrm{K}$ kind of advertising, The equation $\mathrm{w}_{\mathrm{k}}=1$ means that sellers chose the $\mathrm{K}$ kind of advertising, Similarly $\mathrm{w}_{\mathrm{k}}=0$ means that sellers had not chosen the $\mathrm{K}$ kind of advertising. The impact of the degree of influence of each kind of advertisement to the commodity is not the same, that is, the way each ad has its own weight coefficient. Thus, the weight coefficient vector of $\mathrm{W}$ is formed. In this paper, $\mathrm{R}$ is used to represent the weight coefficient vector of $\mathrm{W}$. $\mathrm{R}=$

$\left(r_{1}, r_{2}, r_{3} \ldots . . r_{n}\right), r_{i} \in[0,1]$. The author uses $P$ to express the influence degree of the advertisement propaganda way, because all kinds of advertisement way influence the commodity to the commodity has the accumulation, then gets the calculation formula $\mathrm{P}$ which is as follows:

$$
\mathrm{P}=\mathrm{W} \cdot \mathrm{R}^{\mathrm{T}}=\frac{\sum_{\mathrm{k}=1}^{\mathrm{n}} \mathrm{w}_{\mathrm{k}} \cdot \mathrm{n}_{\mathrm{k}}}{\mathrm{n}}
$$

\section{Contribution of commodity properties}

If its understanding of the properties of the goods is not sufficient, the recommendation of the system with the recommended function is wrong, and it affects customer satisfaction. In addition, the search engine, in search of the time gives the right commodity a position in the back, affecting the accuracy of the search.

It is very complex to analysis attributes quantization of commodities. Understanding of the goods and accept is a top-down, stepwise refinement. Each attribute of the commodity has its own set of values. We set up the commodity attribute vector $U=\left(U_{1}, U_{2}, U_{3} \ldots U_{m}\right)$, where $m$ is the total number of commodity attributes, as well as the corresponding weight coefficient $S=\left(s_{1}, s_{2}, s_{3}, \ldots . . s_{m}\right)$, $\mathrm{s}_{1}+\mathrm{s}_{2}+\mathrm{s}_{3} \ldots . .+\mathrm{s}_{\mathrm{m}}=1$, which makes I take $(1,2 \ldots \ldots \mathrm{m})$. Then the $\mathrm{U}_{\mathrm{i}}$ corresponds to its own set of values, the value of the $\mathrm{U}$ attribute is set to: 


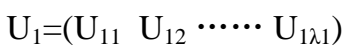

$$
\begin{aligned}
& \mathrm{U}_{2}=\left(\begin{array}{llll}
\mathrm{U}_{21} & \mathrm{U}_{22} & \cdots \cdots & \mathrm{U}_{1 \lambda 2}
\end{array}\right)
\end{aligned}
$$

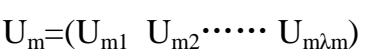

Where $\lambda \mathrm{i}$ represents the total number of the value set of the $\mathrm{i}$-th commodity attributes. We get the value of $\mathrm{j}$ from the set $(1,2 \cdots \cdots \mathrm{m})$, then the $U_{\mathrm{ij}}$ corresponds to the specific, detailed $\mathrm{j}$-th value of the i-th attribute of the commodity. Each attribute of the commodity can only take one value from the corresponding value set. The value of each attribute is different, the corresponding user acceptance is different, that is to say, the degree of contribution of each value of each attribute of commodity to confidence is different. We set the matrix of the degree of the contribution of each specific attribute value corresponding to user's acceptance as:

$$
\begin{aligned}
& \left(\begin{array}{llll}
t_{11} & t_{12} & \cdots \cdots & t_{1 \lambda 1}
\end{array}\right) \\
& \left(\begin{array}{llll}
\mathrm{t}_{21} & \mathrm{t}_{22} & \cdots \cdots & \mathrm{t}_{2 \lambda 2}
\end{array}\right) \\
& \left(\begin{array}{llll}
t_{\mathrm{m} 1} & \mathrm{t}_{\mathrm{m} 2} & \cdots \cdots & \mathrm{t}_{\mathrm{m} \lambda \mathrm{m}}
\end{array}\right)
\end{aligned}
$$

Where $t_{i j}$ represents the contribution of the corresponding attribute value $U_{i j}, 0<=t i j<=1$.

We use $Q$ to represent the contribution of product attributes, then $Q$ is calculated as:

$$
\mathrm{Q}=\mathrm{s}_{1} \times \mathrm{t}_{1 \mathrm{j}}+\mathrm{s}_{2} \times \mathrm{t}_{2 \mathrm{j}}+\mathrm{s}_{3} \times \mathrm{t}_{3 \mathrm{j}} \cdots \cdots \cdot \mathrm{s}_{\mathrm{m}} \times \mathrm{t}_{\mathrm{mj}}
$$

\section{Calculation of comprehensive confidence level of product confidence model}

The value of the integrated confidence of the commodity confidence model can be calculated by the following formula:

$$
(\alpha \times \mathrm{P} \mid \beta \times \mathrm{Q}) / 2
$$

In this formula, $\alpha$ is the advertising effect of weight coefficient, $0<\alpha<1 ; \beta$ is commodity attribute support degree of weight coefficient, $0<\beta<1, \alpha+\beta=1$.

\section{Relationship between weight coefficient and comprehensive evaluation}

Fuzzy comprehensive evaluation method is introduced in this paper. In order to facilitate the user's evaluation, we use the percentile system to evaluate the weight.we can set $\alpha^{\prime}$ as an evaluation of the effect of the advertising and publicity way, $\beta$ ' as the evaluation of the contribution of the commodity attribute. The relationship of $(\alpha, \beta)$ and $\left(\alpha^{\prime}, \beta^{\prime}\right)$ is as follows:

$$
\alpha=\frac{a^{\prime}}{\alpha^{\prime}+\beta} \quad \beta=\frac{\beta^{\prime}}{\alpha^{\prime}+\beta}
$$

we can assume the evaluation vector of the weight set of influence degree vector $R$ of advertising style as $\mathrm{R}^{\prime}=\left(\mathrm{r}_{1}{ }^{\prime}, \mathrm{r}_{2}{ }^{\prime} \ldots \ldots \mathrm{r}_{\mathrm{n}}{ }^{\prime}\right)$. The relationship of $\mathrm{r}_{\mathrm{k}}$ and ${ }^{\mathrm{r}_{\mathrm{k}}}$ ' is as follows:

$$
\mathrm{r}_{\mathrm{k}}=\frac{\mathrm{r}_{\mathrm{R}}}{100}
$$

$S^{t}$ is used to represent the first level of commodity attribute of confidence contribution degree vector $V$ of weight score vector. $S^{\prime}=\left(s_{1}{ }^{\prime}, s_{2}{ }^{\prime}, s_{3}{ }^{\prime} \cdots \cdots \cdot s_{m}{ }^{\prime}\right)$. The relationship of $s_{1}$ and $s_{i}^{\prime}$ is as follows

$$
s_{i}=s_{i}^{\prime} / \sum_{i=1}^{m} s_{i}^{\prime}
$$

Scoring matrix of the second layer attribute weight of the product is set as follows:

$$
\begin{aligned}
& \left(\begin{array}{ccccc}
t_{11}^{\prime} & t_{12}^{\prime} & \cdots \cdots & t_{1 \lambda 2}^{\prime} \\
\left(t_{21}^{\prime}\right. & t_{22}^{\prime} & \cdots \cdots & t_{2 \lambda 2}^{\prime}
\end{array}\right) \\
& \left(\begin{array}{cccc}
t_{m}^{\prime} & t_{m 2}^{\prime} & \cdots \cdots & t_{m i m}^{\prime}
\end{array}\right)
\end{aligned}
$$

The relationship of $t_{i j}$ and ${ }^{t_{i j}}$ is as follows:

$$
\mathrm{t}_{\mathrm{ig}}=\frac{\mathrm{i}_{\mathrm{i}}}{100}
$$




\section{Experimental investigations}

In the research of confidence degree of the instant noodles for student groups, the author conducted a practical investigate. The concerned properties are three attributes of the brand, taste, packaging, that is, $m=3$. We launched a questionnaire survey, using a hundred percent evaluation, and counted the arithmetic average of the score from the received questionnaires. the results are as shown in table 1 , table 2 , and table 3 :

Table 1 The statistics on the score to the weight

\begin{tabular}{|c|c|c|}
\hline name & weight & $\begin{array}{l}\text { The average user 's score to the } \\
\text { weight }\end{array}$ \\
\hline $\begin{array}{c}\text { The influence degree of the way of } \\
\text { commodity advertisement }\end{array}$ & $\alpha$ & 35.256 \\
$\begin{array}{c}\text { The degree of contribution of commodity } \\
\text { attributes }\end{array}$ & $\beta$ & 56.673 \\
\hline
\end{tabular}

Table 2 The statistics on the score of the weight of the advertisement propaganda way

\begin{tabular}{|c|l|l|c|}
\hline Variable name & advertisement propaganda way & weight & $\begin{array}{l}\text { The average user 's score to the } \\
\text { weight }\end{array}$ \\
\hline $\mathrm{w}_{1}$ & mass text messages & $\mathrm{r}_{1}$ & 48.806 \\
\hline $\mathrm{w}_{2}$ & leaflets & $\mathrm{r}_{2}$ & 55.968 \\
\hline $\mathrm{w}_{3}$ & television ads & $\mathrm{r}_{3}$ & 72.097 \\
\hline
\end{tabular}

Table 3 The statistics on the score of the weight of the degree of contribution to the commodity

\begin{tabular}{|c|c|c|c|c|c|c|}
\hline \multicolumn{7}{|c|}{ attributes } \\
\hline $\begin{array}{l}\text { Variable } \\
\text { name }\end{array}$ & $\begin{array}{l}\text { The } \\
\text { properties } \\
\text { of instant } \\
\text { noodles }\end{array}$ & weight & $\begin{array}{l}\text { The } \\
\text { average } \\
\text { user 's } \\
\text { score to } \\
\text { the } \\
\text { weight }\end{array}$ & $\begin{array}{l}\text { Value set of } \\
\text { attributes }\end{array}$ & $\begin{array}{l}\text { Contribution } \\
\text { degree }\end{array}$ & $\begin{array}{l}\text { The } \\
\text { average } \\
\text { user 's } \\
\text { score }\end{array}$ \\
\hline \multirow{6}{*}{$\mathrm{U}_{1}$} & \multirow{6}{*}{ brand } & \multirow{6}{*}{$\mathrm{S}_{1}$} & \multirow{6}{*}{43.258} & BAIXIANG & $\mathrm{t}_{11}$ & 43.548 \\
\hline & & & & KANGSHIFU & $t_{12}$ & 75.774 \\
\hline & & & & TONGYI & $t_{13}$ & 56.903 \\
\hline & & & & HUAFENG & $\mathrm{t}_{14}$ & 41.194 \\
\hline & & & & BAIJIAFENGSI & $\mathrm{t}_{15}$ & 40.032 \\
\hline & & & & GONGZAIMIAN & $\mathrm{t}_{16}$ & 48.433 \\
\hline \multirow{7}{*}{$\mathrm{U}_{2}$} & \multirow{7}{*}{$\begin{array}{l}\text { the flavor or } \\
\text { taste }\end{array}$} & \multirow{7}{*}{$\mathrm{S}_{2}$} & \multirow{7}{*}{49.573} & chops & $t_{21}$ & 54.097 \\
\hline & & & & beef & $t_{22}$ & 58.355 \\
\hline & & & & spicy and hot & $t_{23}$ & 49.742 \\
\hline & & & & dried mushroom & $t_{24}$ & 57.581 \\
\hline & & & & chicken & $t_{25}$ & 48.871 \\
\hline & & & & sauerkraut & $t_{26}$ & 59.065 \\
\hline & & & & fish and Shrimps & $t_{27}$ & 46.903 \\
\hline \multirow[t]{2}{*}{$\mathrm{U}_{3}$} & \multirow[t]{2}{*}{ package } & \multirow[t]{2}{*}{$\mathrm{S}_{3}$} & \multirow[t]{2}{*}{60.239} & box-packed & $t_{31}$ & 75.419 \\
\hline & & & & packet & $t_{32}$ & 52.326 \\
\hline
\end{tabular}

We put data $\alpha^{\prime}=35.256, \beta^{\prime}=56.673$ in the table 1 into the formula 4 to get the results $\alpha=0.384$, $\beta=0.616$, and then put data $\mathrm{r}_{1}{ }^{6}=48.806, \mathrm{r}_{2}{ }^{6}=55.968, \mathrm{r}_{3}{ }^{6}=72.097$ in the table 2 into the formula 5 to get the results $r_{1}=0.488064516, r_{2}=0.559677419, r_{3}=0.720967742$. From the table can be known, $\mathrm{w}_{1}=1, \mathrm{w}_{2}=1, \mathrm{w}_{3}=1, \mathrm{n}=3$. We put them into the formula 1 to get $\mathrm{P}=0.58957$.

We put data $\mathrm{s}_{1}{ }^{6}=43.258, \mathrm{~s}_{2}{ }^{6}=49.573, \mathrm{~s}_{3}{ }^{6}=60.239$ in the table 3 into the formula 6 to get the results $\mathrm{s}_{1}=0.282602731, \mathrm{~s}_{2}=0.323858365, \mathrm{~s}_{3}=0.393538904$. For example, now we are required to 
calculate the contribution degree of product attributes of HUAFENG brand boxed beef flavor instant noodles. We put data $\mathrm{t}_{14}^{\prime}=41.194, \mathrm{t}_{22}^{\prime}=58.355, \mathrm{t}_{31}^{\prime}=75.419$ in the table 3 into the formula 7 to get the results $\mathrm{t}_{14}=0.41194, \mathrm{t}_{22}=0.58355, \mathrm{t}_{31}=0.75419$, and then put them into the formula 2 to get $\mathrm{Q}=$ $\mathrm{s}_{1} \times \mathrm{t}_{14}+\mathrm{s}_{2} \times \mathrm{t}_{22}+\mathrm{s}_{3} \times \mathrm{t}_{31}=0.602206$. Then we can use the values of $\mathrm{P}$ and $\mathrm{Q}$ into the formula 3 , finally calculate that the confidence level of instant noodles is 0.298676895 .The recommendation system, when it recommended the new instant noodles, can put confidence degree as the standard for recommendation.

\section{Conclusions}

In this study, the commodity confidence level for the latter part of the commodity recommendation research and commercial search engine development has laid a foundation. In the studies of commodity recommendation process, before goods sold into the market, since the goods haven't been sold, according to the sales amount, recommendation is not valid, for new products. However, according to the commodity the confidence to do recommend, thus avoiding the unfair phenomenon in new product recommendation, otherwise it will cause new listing commodity is always behind the recommended sequence.

\section{Acknowledgements}

This work was financially supported by the Project of Natural Science Foundation of Hainan Province (20166232)

\section{References}

[1] Xiaoyong Du,Man Li,Shan Wang. Summary of research on Ontology Learning[J].Journal of software,2006,17(9):1837-1847.

[2]Dan Liu,Qingsheng Xie,Xinjian Gu. Research on the construction technology of product ontology in the electronic commerce environment[J]. Computer application,2007, 27(3) : 752-755.

[3]HEPP M. Products and services ontologies: a methodology for deriving owl ontologies from industrial categorization standards[J].International Journal on Semantic Web and Information Systems,2006,2(1) : 72-99.

[4]LEE T,LEE I,LEE S,et al.Building an operational product ontology system[J].Electronic Commerce Research and Applications,2006,5(1) : 16-28.

[5]LEE H,SHIM J,KIM D.Ontological modeling of e-catalogs using EER and description logics[C] // International Workshop on Data Engineering Issues in E-Commerce,IEEE.[S. 1.]: [s. n.],2005: 125-131.

[6]KIM W,CHOI D,PARK S.Product information meta-search framework for electronic commerce through ontology mapping[C]// The Semantic Web: Research and Applications.[S. 1.]: [s. n. ] ,2005: 127-132.

[7]VEGETTI M,HENNING G P,LEONE H P.A PDM system for the derivation of products with complex structure in process industries[C] // Proceedings of the 33 JAIIO.[S. 1.]:[s. n.],2004: 1-10.

[8]RAYMOND LYK.Fuzzy domain ontology discovery for business knowledge management[J].IEEE Intelligent Informatics Bulletin,2007,8(1) : 29-41. 